\title{
A K-BAND LUMINOSITY FUNCTION OF HICKSON COMPACT GROUPS OF GALAXIES
}

\author{
S. NISHIURA, T. MURAYAMA AND Y. TANIGUCHI \\ Astronomical Institute, Tohoku University \\ Y. SATO \\ ISAS and VILSPA \\ AND \\ D.B. SANDERS \\ Institute for Astronomy, University of Hawaii
}

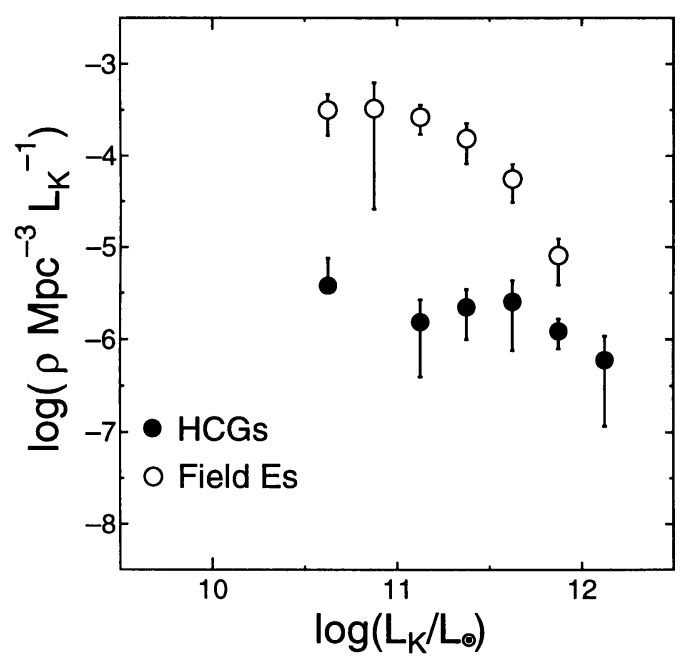

Figure 1. A K-band luminosity function of Hickson Compact Groups of Galaxies. The data were obtained at the University of Hawaii Planetary Patrol 24 inch telescope with a NICMOS3 camera. The K-band luminosity function of field ellipticals are derived from the data in Faber et al. $(1989, A p J S, 69,763)$. We adopted 4.19 mag. as $(B-K)_{\mathrm{T}}^{0}$ of ellipticals (as estimated from Govazzi \& Boselli 1996, Astro. Lett. \& Comm., 35, 1) 